\title{
Analysis on Regional Differences of Economic Development in Shandong Province
}

\author{
Zongliang Zhang \\ Linyi University, Lin Yi, Shan Dong, 276000 \\ hunter2011@foxmail.com
}

Keywords: Regional Economic Disparities; Shandong

\begin{abstract}
Shandong Province is also one of the provinces with more serious regional economy differences in the domestic. The regional economic disparities are obvious in Shandong Province and it is widening and with the rapid expansion of the absolute difference, but the relative difference is in steady development. The main causes of the difference are differences of resource around the city, physical capital, human capital and in industrial structure around the city.
\end{abstract}

\section{Introduction}

Located in China's eastern coastal, Shandong is an economic and populous province. However, due to various factors, from coastal areas to inland Shandong Province, the level of economic development presents different levels, such as significant differences in economic development, affecting the overall economic efficiency of Shandong Province increased. Therefore, the regional economic difference of Shandong Province and countermeasures research, can provide some theoretical and policy advice and build a "harmonious Shandong" coordinated development of regional economy in Shandong province, it has important practical significance [1].

\section{The Overview of Regional Economic Differences in Shandong Province}

Shandong Province is located in the Yellow River estuary, Bohai Sea and the Yellow Sea, to the mountains dominated the Midwest, primarily in eastern plains, favorable natural conditions, a good economic basis, industrial strength. Our overall economic strength has been ranked the forefront of rapid economic growth for China's GDP growth has made outstanding contributions, but at the same time their overall rapid economic development, between regions in the province, but there is a great imbalance, "West Low East High, "a serious impediment to the province's well-off society and build" to promote harmony in Shandong "social objectives.

\section{Research Contents and Methods}

Research Regional and Content. Taking into account the huge difference with county and municipal districts and county-level city in the industrial structure, employment structure, etc., take 17 cities in the geographical unit to carry out the research, and accordingly differences in economic development of the province's issues analysis. Provincial research to measure the level of economic development of the mainland market as the core, including the construction of regional economic development evaluation index system of 17 ground level of the city economic development of an integrated measurement and analysis, and coordinating regional economic development countermeasures.

Index System. Differences evaluation of regional economic development, we must establish appropriate indicators. Follow the principle of comprehensiveness, the dominant principle, scientific principle, the principle of comparability, feasibility principle and the principle of relativity, and in accordance with the economic development of the target layer constructed level of development, industrial structure, productivity, foreign economic and living standard of the five sub-system, and ultimately select the per capita GDP, primary industry proportion of GDP, to all 18 
indicators of GDP, the total value of exports per capita of urban residents per capita disposable income to build a regional economic development evaluation index system [2].

Research Methods. At present, there are a lot of academic methods for comprehensive evaluation, commonly used analytic hierarchy process, factor analysis, fuzzy comprehensive evaluation method and the like. In order to reduce and eliminate the effect of certain subjective factors evaluation process, using mean variance weighting method to the extent of regional economic development in Shandong comprehensive measure, and accordingly to the regional economic development were analyzed. The specific steps are as follows:

(1) Raw data standardization. Bring a different dimension to eliminate non-comparative index, use the poor standardized method to standardize the raw data.

(2) Calculate standards of various indicators.

(3) Calculate the index in which the right to sub-standard deviation based on the weight of each indicator.

(4) Score is calculated for each subsystem, the formula is as follows:

$$
S_{i k}=\sum_{i=1}^{m}\left(W_{k j} \times Y_{i j}\right)
$$

Where: $S_{\mathrm{i} k}$ cities a $k$ represents the value system layer; $W_{k j}$ represents the $k$ system layer right item $\mathrm{j}$ target weight value; $Y_{i j}$ item $\mathrm{j}$ index value represents the $i$-th city (normalized value); $\mathrm{m}$ represents the first the number of index $\mathrm{k}$ system layer contains.

(5)The five sub-systems as five constituent elements of the target layer, repeat the above(2)(3)(4) the process is obtained target layer composite score [3].

\section{Results of the Evaluation}

The presence of the level of economic development of Shandong 17 cities in obvious differences, spatial differentiation is very significant. A higher level of economic development in Shandong cities mainly in the east coast and along the Jinan Railway, and the level of economic development in the western inland is not high. Weihai, Qingdao, Yantai, located in the eastern coastal areas, the development of early history, convenient external traffic, Dongying is a resource-based cities, oil extraction and processing play an important role in the city's economy, so the higher the level of economic development in four cities; Texas, Liaocheng, Shandong Heze is located in the western inland, poor location, economic development history of late, the foundation is weak, foreign and inaccessible, so a low level of economic development. Taken together, all located in the eastern coastal areas, transport facilities, develop early history, relatively solid economic foundation of the city, such as Weihai, Qingdao, Dongying, Yantai, its high economic development index scores; all located in the western inland, Foreign inaccessible region blocked the flow of the city, such as Texas, Liaocheng, Heze, low economic development index score.

\section{Countermeasures of Regional Economic Development}

Face up to Regional Differences and Pay Attention to the Efficiency of Economic Development. In the process of socio-economic development, equity and efficiency are one of the core issues of regional studies economic decisions. Developed countries also experienced a fair exchange for efficient processes, which are selective focus initial development and construction of the most advantages and development potential of the region, when the economic level reaches a certain level, an emphasis on equity. Coordinated regional development system is always in a "balanced state Non-Equilibrium State higher equilibrium state" in the process of evolution. Since the reform and opening up, Shandong inclined to take appropriate development strategy, the economy developed rapidly [4].

Adhere to the "Point - Axis" Development Mode and Optimizing Spatial Structure. "Point - axis" development model is the most effective form of economic organization of space, combined with the specific situation in the province of Shandong, Jinan Railway chosen for the 
development axis, further promote the economic development of Qingdao, Jinan, Zibo city, select Qingdao, Jinan point for the development of full use of the advantages of open coastal cities of Qingdao port, play the comprehensive function of the capital city of Jinan, as an axis of economic growth and focus on the development of the province. Achieve a point to line to line pro side, to play a "point - - axis" spillover effects systems, and promote the formation of industrial belt, driving the province's economy healthy and rapid development. When the economy develops to a certain extent, in a province-wide perspective, with strong material and technological foundation, the factors of production flow network, transportation network, communications networks, etc. has been formed.

Optimize the Industrial Structure and Promote Regional Economic Development. By the end of 2006, Shandong's industrial structure as a whole to achieve the transition to a modern industrial structure, but because of the imbalance in regional development, low level of industrial structure individually city. To further optimize the industrial structure of Shandong and coordinate regional economy and should continue to develop agriculture and promote agricultural industrialization development. Another is actively promoting the adjustment of the interior industrial structure. Last but not the least is vigorously developing the tertiary industry. Continue to strengthen the circulation of commodities, information and development of transportation and tourism industry, and further promote the development of finance and insurance, information consulting and other emerging industries.

The Implementation of "Science and Education " Strategy. The role of science and technology in economic development increasingly significant, scientific and technological level and improve the quality of the population is the backbone of economic development. At present, Shandong higher education is relatively backward, population quality to be improved. Although there are many colleges and universities in Shandong, but not much subordinates major colleges and universities. Therefore, Shandong should accelerate the development of science and technology education, rely on science and technology, education and gradually resolve the contradiction in all aspects [5].

\section{Conclusion}

Regulation of the target area in Shandong Province should be slowed economic disparities widening economic disparities in the region, to prevent disorder caused by the province's economic development and lead to social unrest, at the same time, by increasing the underdeveloped foster regional economic development efforts, aimed at bridging the region the difference between the economy and the absolute relative difference. And to achieve this goal, we must develop coordinated regional economic development policies, it is necessary to maintain the province's coastal spurring economic growth, but also to accelerate the development of the western areas of Shandong Province.

\section{References}

[1] Wu D.T. Systematic Analysis of Economic Growth Differences of China's Three Areas.Areal Research and Development .2001, 20(2):10-15.

[2] Zhou Y.C. The Dynamic Characteristics of Inter-Provincial Economic Difference in Nearly 10 Years in China. Geographical Research, 2002, 21(6):781-190.

[3] Tan C L. Spatial Characteristics of Regional Economic Differences and the Policy Implications. Areal Research and Development. 2008, 1(9).

[4] Wei H.K. The Theoretical Forefront of Contemporary Regional Economic Studies. Development Research. 1998 (1).

[5] Li J.H. Regional Economic Growth. Productivity Research, 2007 (7). 